Article

\title{
Experimental Study on Catalytic Combustion of Methane in a Microcombustor with Metal Foam Monolithic Catalyst
}

\author{
Yanxia Li ${ }^{1}$, Chaoming Luo ${ }^{1,2}$, Zhongliang Liu ${ }^{1, * \mathbb{C} \text { and Feng Lin }}{ }^{2}$ \\ 1 MOE Key Laboratory of Enhanced Heat Transfer and Energy Conservation, Beijing Key Laboratory of Heat \\ Transfer and Energy Conversion, College of Environmental and Energy Engineering, Beijing University of \\ Technology, Beijing 100124, China; liyanxia@bjut.edu.cn (Y.L.); zjfylcm@163.com (C.L.) \\ 2 Energy Supervision Unit (Centre) of Tonglu, Hangzhou 311501, China; lin_feng_223@163.com \\ * Correspondence: liuzhl@bjut.edu.cn; Tel.: +86-10-67392774
}

Received: 10 October 2018; Accepted: 8 November 2018; Published: 12 November 2018

check for updates

\begin{abstract}
Utilizing catalysts in microcombustors is probably an excellent practical solution to stabilize fuel combustion because of the relatively fast reaction speed. In the present work, the monolithic catalyst $\mathrm{Pd} / \mathrm{A}_{2} \mathrm{O}_{3} / \mathrm{Fe}-\mathrm{Ni}$ with metal foam as matrix was used inside a $5 \mathrm{~mm}$ in diameter microcombustor. Then the effects of inlet velocity and equivalent ratio on catalytic combustion characteristics of methane were studied experimentally. The results showed that the methane and air mixture with the stoichiometric ratio $\Phi=1.0$ could be ignited at $v=0.2-0.6 \mathrm{~m} / \mathrm{s}$. The velocity of premixed mixture had a great influence on the catalytic combustion of methane. The larger the inlet velocity, the higher the temperature and the brighter the flame were. The experiment results also showed that the equivalence ratio had a large essential impact on the catalytic combustion, especially for the lean mixture of methane and air. It seemed the addition of the porous matrix with catalysts could significantly extend the limits of stable combustion. In the detection of exhaust gas, $\mathrm{CO}$ selectivity increased and $\mathrm{CO}_{2}$ selectivity decreased with the equivalence ratio. When $\Phi$ was between 0.94 and $1.0 \mathrm{~m} / \mathrm{s}$, a little amount of hydrogen was produced due to the lack of oxygen. The measured conversion of methane to $\mathrm{CO}$ and $\mathrm{CO}_{2}$ was very high, usually greater than $99 \%$, which indicated the excellent performance of the catalyst.
\end{abstract}

Keywords: catalytic combustion; methane; monolithic catalyst; metal foam substrate

\section{Introduction}

With the rapid development of microelectromechanical systems (MEMS), the demands for miniaturized power sources are growing quickly. Now the traditional lithium batteries are widely used. However, they cannot satisfy the demand of MEMS for power sources. Hydrocarbon fuels have much higher energy density than batteries. For example, the advanced currently available lithium ion batteries have an energy density of $0.2 \mathrm{kWh} / \mathrm{kg}$, which is only $1 / 60$ that of methane [1]. In addition, hydrocarbon fuels are cheap and environmentally friendly. Thus, using combustion-based micropower generation systems to drive the MEMS is a good and promising choice in the future. The microcombustors using hydrocarbons as fuel are a key component and may play a vital role in the portable production of energy. However, due to intensified heat loss from the flame to the combustor wall, radical destruction at the gas-wall interface, and reduced residence time compared to the traditional combustors, combustion in microcombustors usually becomes unstable and inefficient [2].

Porous matrix-stabilized combustion refers to the mixture of fuel and oxidizer burning within a solid porous inert medium. The associated technology, matrix-stabilized porous medium combustion, 
has been brought into focus due to its advantages, such as extended lean flammability limits, low pollutant emissions, and high flame temperature and speed [3,4]. The porous inert medium combustion can obtain a higher flame temperature than thermodynamic equilibrium adiabatic values. This is because the porous inert medium within a burner can transfer the heat from the hot products in the post-flame zone upstream to preheat incoming reactants, and this is why it is also called super adiabatic combustion. Besides, the porous medium plays an important role in heat accumulation, which helps the lean mixtures stabilize the flame and makes the flammability limits lower. A great number of studies report on combustion using porous burners [3-6]. Generally speaking, $\mathrm{SiC}$ or $\mathrm{Al}_{2} \mathrm{O}_{3}$ honeycomb is inserted as the porous matrix inside the porous combustion burner. However, only a few studies on catalytic combustion within porous burners can be found.

Heat loss is one of the most important factors in small-scale combustors because of the high surface area-to-volume ratio that increases with a reduction in combustor size. Another inherent difficulty in microcombustion systems is the very short residence time within the combustors, which means a relatively short reaction time for reactants. During the past decade, a lot of effort has been expended on investigating the effects of catalyst addition on extinction limits and thermal performance of small catalytic combustors. It has been reported that utilizing a catalyst in a microcombustor is an excellent possible solution to widen the range of operating conditions and help stabilize fuel combustion [7-10].

Coating catalysts on the surface of porous inert mediums could enhance the performance of combustion within a porous burner. On the one hand, the high surface to volume ratio that is characteristic of porous mediums is especially suitable for using catalysts, as the increased surface area favors catalytic combustion by providing more sites upon which the fuel and oxidizer can adsorb. On the other hand, the catalysts can widen the range of stable operating conditions, lower the ignition and combustion temperatures, and increase the hydrocarbon oxidation rates.

Metallic foams have attracted attention over the past decades because of their advanced features both thermophysically and mechanically. They have low masses, large specific surfaces, high permeability, and large effective thermal conductivities. Several kinds of metal foams have been used as substrates for structured catalysts in reforming methane with carbon dioxide and volatile organic compounds (VOCs) combustion [11-14]. Unfortunately, there are few applications of metal foam-coated catalysts in small and microporous combustion.

To the authors' best knowledge, Spadaccini et al. conducted the first research, where two kinds of metal porous materials were used as substrates of catalysts in their experiments, and found that the addition of a porous platinum catalyst to their microscale gas turbine allowed for an increase in operable mass flow rates through the system, leading to an 8.5-fold increase in power density over the maximum achieved for a noncatalytic system of similar geometry [15]. In addition, in our previous work, we have found that the $\mathrm{Pd} / \mathrm{Al}_{2} \mathrm{O}_{3} / \mathrm{Fe}-\mathrm{Ni}$ metal foam monolithic catalyst exhibited high catalytic activity for methane reaction [16]. Moreover, a study on catalytic combustion within a porous inert medium was performed, in which $\mathrm{SiC}$ porous matrixes coated with perovskite were used to enhance the performance of combustion. Compared to the experiments of nonperovskite-coated porous media, coating the $\mathrm{SiC}$ foams with perovskite catalysts can increase the reaction rate and lower the minimum equivalence ratio [17]. Besides, analysis was also conducted on the effects of $\mathrm{LaMnO}_{3}$ catalysts on startup behavior of porous media combustion by developing computational fluid dynamics (CFD) models [18-20]. It is worth noting that the fully coated monolith provided a faster reaction rate and lower temperature hot spots than partially coated ones and resulted in the front of reactions moving upstream.

In the present work, a metal foam monolithic catalyst $\mathrm{Pd} / \mathrm{A}_{2} \mathrm{O}_{3} / \mathrm{Fe}-\mathrm{Ni}$ was inserted into a quartz glass tube combustor. A piece of $\mathrm{Fe}-\mathrm{Ni}$ alloy metal foam was used as the matrix of the monolithic catalyst, alumina sol $\left(\gamma-\mathrm{Al}_{2} \mathrm{O}_{3}\right)$ was used as the supporter layer, and $\mathrm{Pd}$ was used as the active constituent. The emphasis of this paper was to investigate the catalytic combustion characteristics and the effects of operation conditions, including inlet velocity and equivalence ratio, on catalytic combustion. 


\section{Results and Discussion}

\subsection{Monolithic Catalyst}

A Fe-Ni alloy metallic (70\%Fe-30\%Ni) foam cylinder, purchased from Goodfellow Cambridge Ltd. (Huntingdon, Cambridge, UK), was used for the preparation of the catalyst substrate for methane-air catalytic combustion. The photographs of cylindrical substrate and catalysts are shown in Figure 1. The cylinder had a diameter of $5 \mathrm{~mm}$, a length of $12 \mathrm{~mm}$, an open porosity of $95 \%$, and a cell diameter of $200 \mu \mathrm{m}$. Here, $\gamma-\mathrm{Al}_{2} \mathrm{O}_{3}$ was selected as the supporter and dispersant of Pd. The alumina $\left(\mathrm{Al}_{2} \mathrm{O}_{3}\right)$ sol, prepared from $\mathrm{AlOOH}$ powder and water, was coated on the Fe-Ni alloy metal foam cylinder to enhance the effective surface area and adhesive ability of the catalyst substrate. Then, the $\operatorname{Pd}\left(\mathrm{NO}_{3}\right)_{2}$ solution was dripped onto the $\gamma-\mathrm{Al}_{2} \mathrm{O}_{3}$ layer repeatedly until the palladium loading was $1 \mathrm{wt} \%$. Thus the $1 \% \mathrm{Pd} / 10 \% \mathrm{~A}_{2} \mathrm{O}_{3} / \mathrm{Fe}-\mathrm{Ni}$ catalyst was obtained. The detailed process of preparation of alumina sol and catalyst was described in our previous study $[16,21]$. The prepared catalyst $\mathrm{Pd} / \mathrm{A}_{2} \mathrm{O}_{3} / \mathrm{Fe}-\mathrm{Ni}$ is shown in Figure $1 b$.

From the analysis of microscope pictures, the $\mathrm{Pd}$ catalyst and $\mathrm{Al}_{2} \mathrm{O}_{3}$ coating were uniformly distributed on the porous matrix. Through the detection of crystal structures, the active phase of $\mathrm{Pd} / \mathrm{Al}_{2} \mathrm{O}_{3} / \mathrm{Fe}-\mathrm{Ni}$ catalysts was $\mathrm{PdO}$ even after testing for $30 \mathrm{~h}$ in experiments. This proved that the catalysts prepared in this method were stable and could maintain a high activity for a long period.

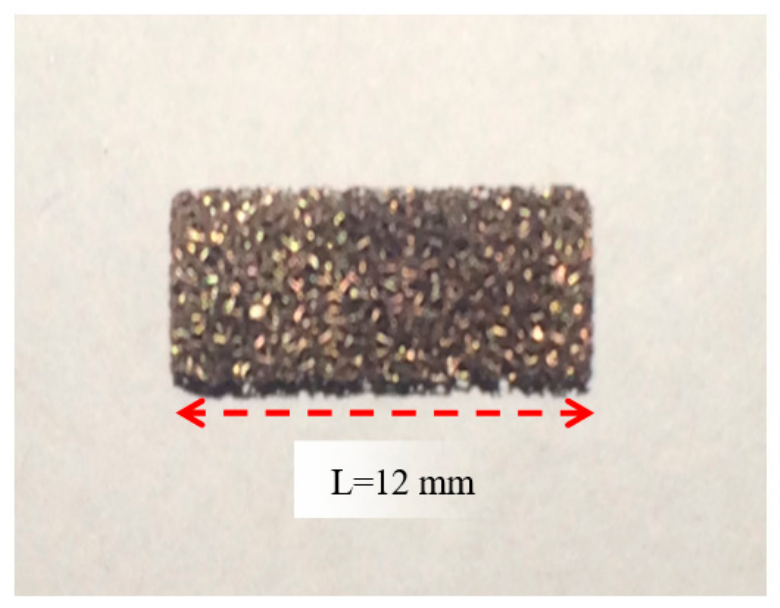

(a) Fe-Ni metal foam substrate

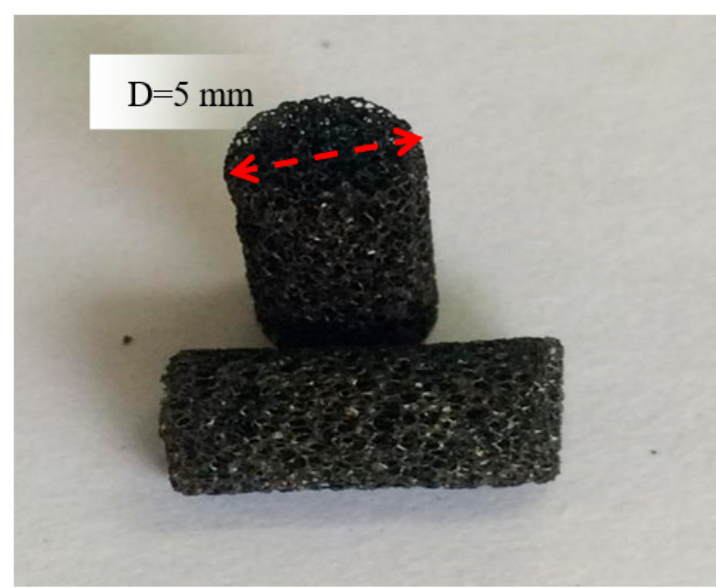

(b) Catalysts $\left(\mathrm{Pd} / \mathrm{A}_{2} \mathrm{O}_{3} / \mathrm{Fe}-\mathrm{Ni}\right)$

Figure 1. Photographs of (a) substrate and (b) catalysts.

\subsection{Startup of Combustion}

The monolithic catalyst $1 \% \mathrm{Pd} / 10 \% \mathrm{~A}_{2} \mathrm{O}_{3} / \mathrm{Fe}-\mathrm{Ni}$ prepared in Section 2.1 was inserted into a single tube combustor to test its catalytic combustion characteristics.

To begin with, the premixed gas of methane and air was ignited by a pair of ignition electrodes that were located at the entrance of the burner (exactly $2 \mathrm{~mm}$ upstream of $T_{1}$, as shown in Section 3.1). The ignition was carried out at room temperature. Seven K-type thermocouples were placed equidistantly to measure the temperature inside the burner. Two pairs of thermocouples, $T_{3}$ and $T_{5}$, were located at the axis of the tube. $T_{3}$ was in front of the catalyst, at the upstream direction of flow. $T_{5}$ was behind the catalyst, at the downstream direction of flow. The other five thermocouples were located along the inner wall of the burner. Equation (1) is

$$
\Phi=\frac{(A / F)_{\text {stoic }}}{(A / F)}=\frac{(F / A)}{(F / A)_{\text {stoic }}}
$$


Figure 2 shows the temperature variation over time after ignition when inlet velocity $v$ was $0.3 \mathrm{~m} / \mathrm{s}$ and equivalence ratio $\Phi$ was 1.0. Equivalence ratio is defined as the actual ratio of fuel to oxidant over the stoichiometric ratio of fuel to oxidant. Its exact definition is given in Equation (1), where $A / F$ is air-to-fuel ratio and $(A / F)_{\text {stoic }}$ is stoichiometric air-to-fuel ratio [22]. The equivalence ratio $\Phi$ is commonly used to indicate quantitatively whether a fuel-oxidizer mixture is rich, lean, or stoichiometric. From this definition, we can see that for fuel-rich mixtures, $\Phi>1$, and for fuel-lean mixtures, $\Phi<1$. That is, if all the fuel had reacted with no excess air, equivalence ratio was at stoichiometry.

It can be seen in Figure 2 that the startup (i.e., the process between ignition and stable combustion) could be divided into three stages. The initial stage (1) was when the high pressure igniter was turned on, and the internal temperature of the burner increased sharply except for $T_{6}$ and $T_{7}$. Due to an intense chemical reaction that took place in the area between the entrance and porous mediums under the ignition of the igniter, a great deal of heat was released in a very short time and made the temperature of the mixture rise rapidly. It should be noted that the temperature of $T_{3}$ was the highest, even higher than $T_{1}$, which was the closest point to the flame. This may be attributed to the heat generation from catalytic oxidation on the surface of the porous medium. The theoretical study performed by Landi et al. also showed that catalytic reaction would occur prior to homogeneous combustion in the startup stage [18]. However, the point of $T_{6}$ and $T_{7}$ was located downstream and far from the flame, so the curves showed a trend of slow rise. The second stage (2) was the internal temperature of the burner dropping slowly. Most of the released heat was carried downstream and the temperature of $T_{6}$ and $T_{7}$ continued to rise slowly. In addition, the heat loss was also an important influence factor, especially for the condition of $v=0.3 \mathrm{~m} / \mathrm{s}$. The heat released by methane combustion was transferred from the burner wall to the environment. The high temperature gas in the burner and the low outside-environment temperature presented a great temperature difference, and therefore heat loss to the environment was inevitable. This heat loss may have been through natural convection and thermal radiation. The large heat loss and heating effects of the combustion explained the quick temperature drop-off and indicated that the system had not achieved its steady state. In the third stage (3), the burner reached the steady state. There was no fluctuation in temperature at all seven points in the burner. This means that the combustion was stable. The picture of flame status will be analyzed in Section 2.3.

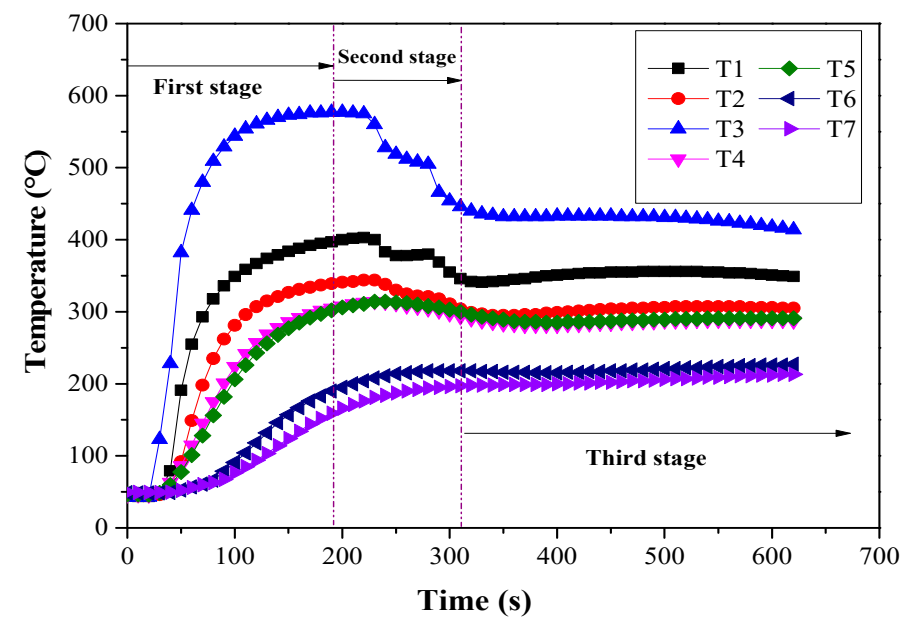

Figure 2. The temperature variation over time after ignition, $v=0.3 \mathrm{~m} / \mathrm{s}$ and $\Phi=1.0$.

\subsection{Effect of Velocity}

From their experiments on the premixed gas combustion of hydrogen and air in a microscale combustor, Zhang et al. [23] found that ignition was very difficult at small flow rates (low velocity), and it was easy to flame out at low velocity. In our work, the smallest inlet velocity was set at $0.2 \mathrm{~m} / \mathrm{s}$. Then, 
the flow rate was increased gradually by $0.1 \mathrm{~m} / \mathrm{s}$ from $0.2 \mathrm{~m} / \mathrm{s}$ to $0.7 \mathrm{~m} / \mathrm{s}$. Under our tested experiment conditions, the results showed that the mixture could be ignited successfully at $v=0.2-0.6 \mathrm{~m} / \mathrm{s}$ and $\Phi=1.0$, and stable combustion flames were also observed. When the inlet velocity increased to $0.7 \mathrm{~m} / \mathrm{s}$, the ignition failed even though several attempts were made. Therefore it could be concluded that the upper limit of the ignition velocity was $v=0.7 \mathrm{~m} / \mathrm{s}$ at $\Phi=1.0$.

Flame pictures were taken with a fixed-height digital camera through the quartz transparent window. Figure 3 shows the photographs of the steady combustion flame at $v=0.2 \mathrm{~m} / \mathrm{s}$ and $\Phi=1.0$. From this figure, we can find that the steady state flame could not be observed in front of the combustion device, and instead a flame was caught obliquely downward (see Figure 3b). What this illustrates is that the flame was located upstream of the ignition electrodes, which were located close to the burner inlet.

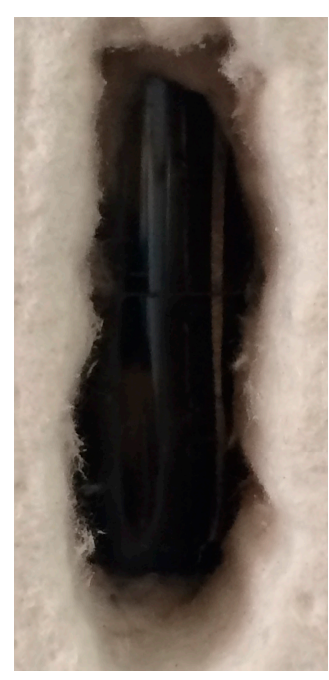

(a)

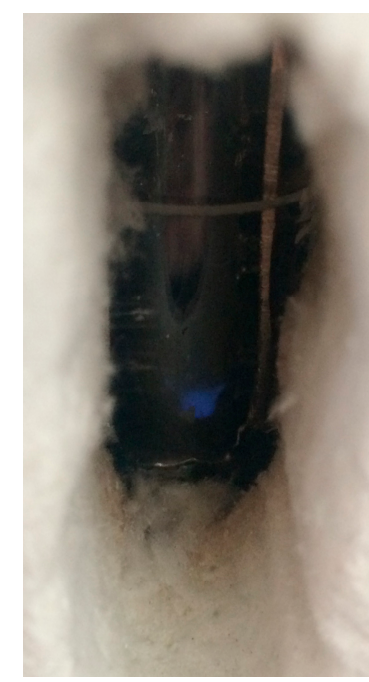

(b)

Figure 3. Photos of stable combustion flame, $v=0.2 \mathrm{~m} / \mathrm{s}$ and $\Phi=1.0$. (a) Front view; (b) oblique view (downward).

The pictures of the location of the stable flame for the premixed mixture at $0.3,0.4,0.5$, and $0.6 \mathrm{~m} / \mathrm{s}$ inlet velocity and 1.0 equivalence ratio are presented in Figure 4 . It can be seen from Figure $4 \mathrm{a}$ that the blue flame was located at the ignition electrodes for the premixed mixture at $0.3 \mathrm{~m} / \mathrm{s}$ inlet velocity and 1.0 equivalence ratio. Compared with $v=0.2 \mathrm{~m} / \mathrm{s}$, the flame of the premixed mixture at $0.3 \mathrm{~m} / \mathrm{s}$ inlet velocity moved downstream. The main reason was that the velocity of the mixed gases was greater than the flame propagation velocity. From Figure $4 a, b$, we can see that the flames at 0.3 and $0.4 \mathrm{~m} / \mathrm{s}$ velocity were all stabilized near the ignition electrodes. However, when the inlet velocity was increased to $0.4 \mathrm{~m} / \mathrm{s}$, the flame of the premixed combustion was brighter and larger than at $0.3 \mathrm{~m} / \mathrm{s}$. The color of the flame partially changed from light blue to red. With the increase in velocity, the quantity of the oxidized methane was increased. Thus, more fuels took part in the combustion reaction and more combustion heat was released. As a result, the flame became brighter compared to $0.3 \mathrm{~m} / \mathrm{s}$. It should be noted further that the flame also appeared at the bottom of the catalyst for mixtures at $v=0.4 \mathrm{~m} / \mathrm{s}$ and $\Phi=1.0$. Perhaps the methane was not fully burned at the entrance of the combustor and the unburnt methane was oxidized on the surface of the catalyst, which was further verified by the results of exhaust gases tests. 


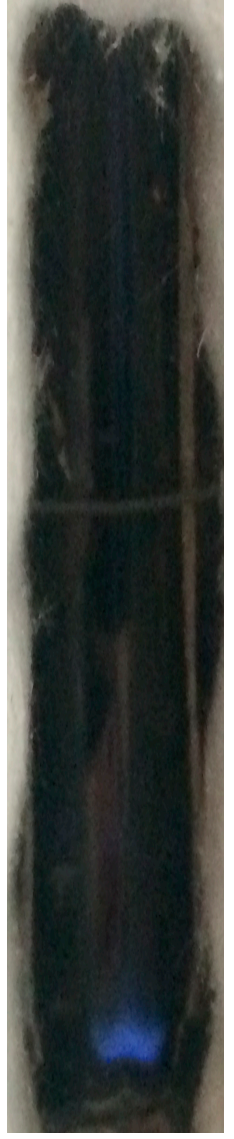

(a) $v=0.3 \mathrm{~m} / \mathrm{s}$

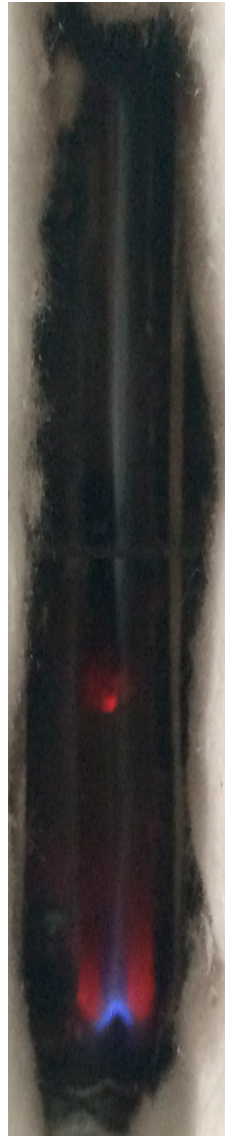

(b) $v=0.4 \mathrm{~m} / \mathrm{s}$

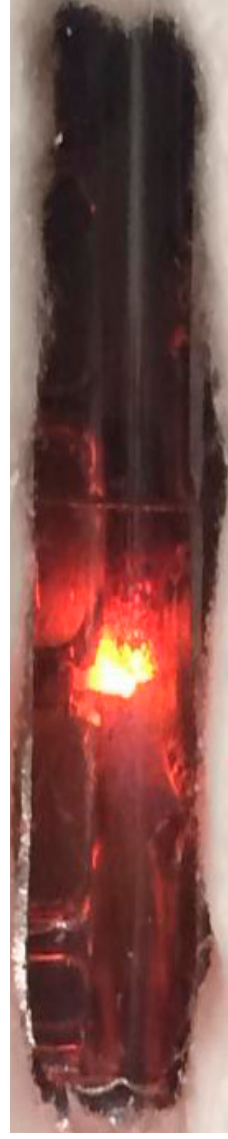

(c) $v=0.5 \mathrm{~m} / \mathrm{s}$

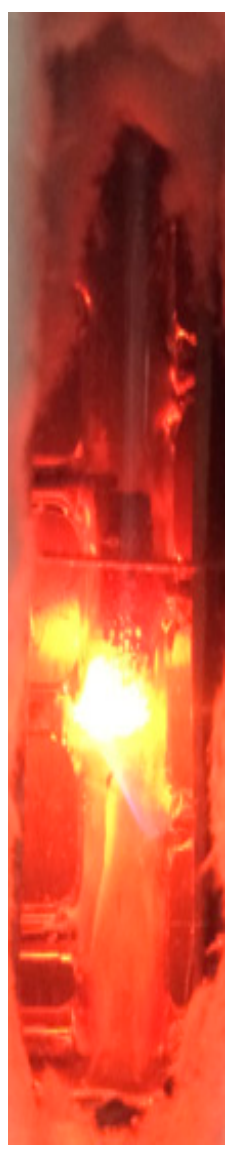

(d) $v=0.6 \mathrm{~m} / \mathrm{s}$

Figure 4. Photos of steady combustion flames with different velocities (front view) at $\Phi=1.0$ : (a) $v=0.3 \mathrm{~m} / \mathrm{s} ;$ (b) $v=0.4 \mathrm{~m} / \mathrm{s} ;$ (c) $v=0.5 \mathrm{~m} / \mathrm{s} ;$ (d) $v=0.6 \mathrm{~m} / \mathrm{s}$.

When the velocity was increased to $0.5 \mathrm{~m} / \mathrm{s}$ and $0.6 \mathrm{~m} / \mathrm{s}$, it can be seen from Figure $4 \mathrm{c}, \mathrm{d}$, that the flames continued moving downstream and were stabilized in front of the catalyst. This is due to the same reason as when velocity was $0.3 \mathrm{~m} / \mathrm{s}$ : The velocity of the mixture was greater than the flame propagation velocity. Compared to the flame at $0.6 \mathrm{~m} / \mathrm{s}$ velocity, the flame at $0.7 \mathrm{~m} / \mathrm{s}$ was brighter and illuminated the combustor, which had the direct result of more methane burning and more combustion heat being released. Accordingly, the temperature increased. As we know, the flame propagation velocity increased with the combustion temperature. When the flame propagation velocity was consistent with the gas flow rate, the flame stabilized at a fixed location. Besides, the catalytic oxidization perhaps played an important role in stabilizing the flame in the front of the catalyst.

Figure 5 shows the internal temperature distribution in the burner. It can be seen from Figure 5 that the temperatures measured by seven thermocouples at $0.4 \mathrm{~m} / \mathrm{s}$ velocity were all higher than those at $0.3 \mathrm{~m} / \mathrm{s}$. It is obvious that the temperature $T_{3}$ was higher than that of the other points because this point was actually located at the axial centerline in front of the catalyst and was the closest to the flame. A similar phenomenon can be found from the temperature distribution at $0.5 \mathrm{~m} / \mathrm{s}$ and $0.6 \mathrm{~m} / \mathrm{s}$, as shown in Figure $5 \mathrm{~b}$. All the seven temperatures at $v=0.6 \mathrm{~m} / \mathrm{s}$ were higher than those at $v=0.5 \mathrm{~m} / \mathrm{s}$. It is surprising that with increasing velocities, more fuel took part in the reaction, and therefore more combustion heat was released. However, the difference in the temperatures between $0.5 \mathrm{~m} / \mathrm{s}$ and $0.6 \mathrm{~m} / \mathrm{s}$ decreased. This was due to the homogenous combustion becoming dominant. Besides, the highest temperature $T_{3}$ climbed from about $580^{\circ} \mathrm{C}$ to about $1100{ }^{\circ} \mathrm{C}$, whereas the temperature in other locations increased relatively slowly. In contrast, the combustion at low inlet velocities involved both homogenous and catalytic combustion, as the faint flames indicated. As stated above, $T_{3}$ was 
located at the centerline and in the flame zone, while $T_{2}$ and $T_{4}$ were along the inner wall, and this explains why the temperature of $T_{3}$ was much higher than $T_{2}$ and $T_{4}$. This was attributed to the temperature inhomogeneity in the radial direction because of the heat loss to the environment.

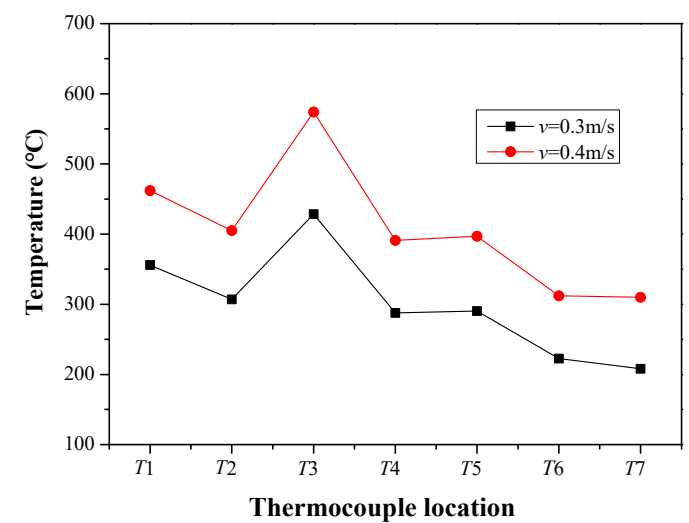

(a)

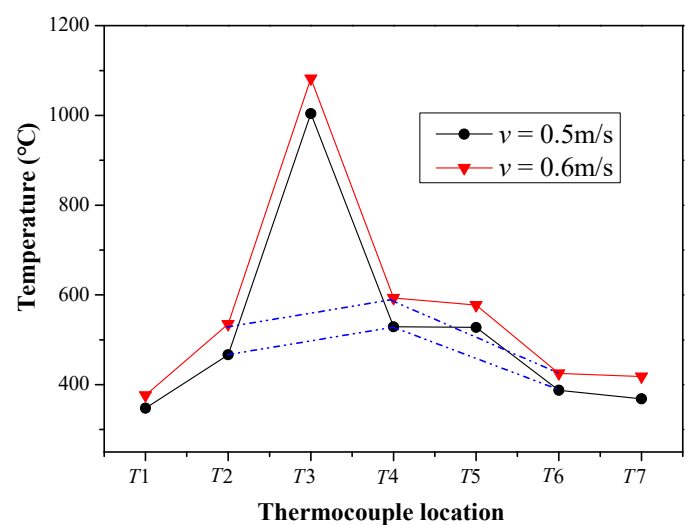

(b)

Figure 5. The temperature distribution of the combustor: (a) the flame was located at the tube inlet of the tube; (b) the flame was located at the front of the catalyst.

\subsection{Effect of Equivalence Ratio}

The equivalence ratio is one of the important parameters that influence the flame position, combustion stability, and temperature distribution in the burner. Herein, the effect of the equivalence ratio on the catalytic combustion of methane was investigated. Figure 6 presents the typical temperature variation over time under the condition that the equivalence ratio reduced slowly. During the experiments, the mixture flow rate remained at a constant and the equivalence ratio decreased regularly from 1.0 to flameout by dropping down the methane flow rate and increasing the air flow rate.

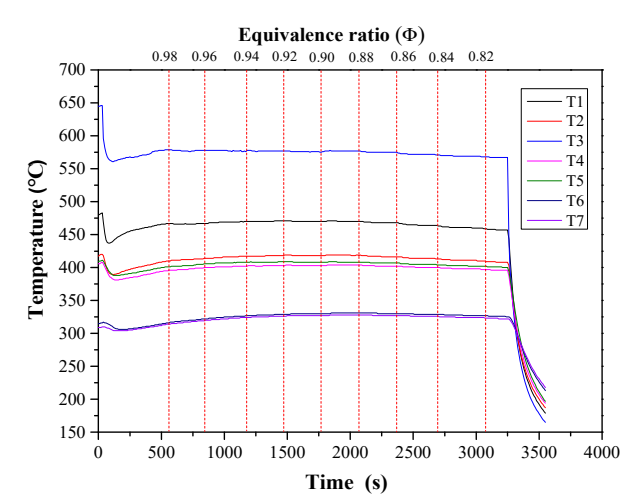

(a)

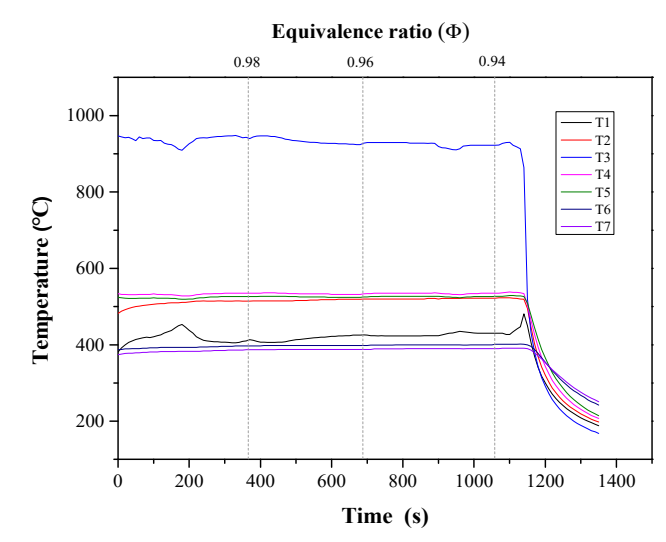

(b)

Figure 6. The temperature variation curve over time: (a) $v=0.4 \mathrm{~m} / \mathrm{s}$ (the flame was located at the tube inlet of the tube); (b) $v=0.5 \mathrm{~m} / \mathrm{s}$ (the flame was located at the front of the catalyst).

At the steady inlet velocity of $v=0.4 \mathrm{~m} / \mathrm{s}$, the temperature dropped suddenly soon after the equivalence ratio was adjusted to 0.82 , which meant that the flame had extinguished. This can be seen obviously in Figure 6a. As we know, equivalence ratio $\Phi$ was the actual ratio of fuel to oxidant over the stoichiometric ratio of fuel to oxidant. As the equivalence ratio $\Phi$ decreased with a fixed flow rate of methane and air mixture, the methane content reduced correspondingly. Thus, the heat released by the methane combustion was too small to sustain a stable combustion. As a result, the flame was 
blown out as the temperature plummeted. For the case of $v=0.5 \mathrm{~m} / \mathrm{s}$, the stable combustion could be observed only in the equivalence ratio range of $0.94-1.0 \mathrm{~m} / \mathrm{s}$. Using the same method, the lower limits of flame extinction for other velocities were measured, as shown in Figure 7 . We can see that the flame extinction limits at $v=0.5 \mathrm{~m} / \mathrm{s}$ were much narrower than in other conditions. This phenomenon involved several complicated factors. In the first place, dominant homogenous combustion had substituted for the synergistic reaction of homogenous and heterogeneous combustion when inlet velocity increased from 0.4 to $0.5 \mathrm{~m} / \mathrm{s}$. At $0.5 \mathrm{~m} / \mathrm{s}$, the effect of flame propagation speed on stable flame became prominent. In fact, the flame propagation speed depended on the temperature in the burning core zone. With the decrease in the equivalence ratio, the methane content dropped down and the combustion heat decreased. This then resulted in the flame retreating out of the porous medium with catalysts. At this time, the flame became unstable and easy to extinguish. Second, the porous matrix with the Pd catalyst played an essential role in the confined combustion (the diameter of the tube combustor was $5 \mathrm{~mm}$ ). For the low flow rate conditions, the flames were contained near the entrance $(v=0.3 \mathrm{~m} / \mathrm{s})$, and the porous media could oxidize the unburnt fuel and keep heat inside the combustor. As the mixture flow rate increased from 0.3 to $0.4 \mathrm{~m} / \mathrm{s}$, the homogenous combustion took place at the entrance due to the low flame propagation speed. The intense catalytic combustion also happened in front of the porous matrix, which was beneficial for stabilizing the flame. Even though the methane content decreased with the decrease of the equivalence ratio, the chemical reaction could concentrate at the entrance. But in the case of $0.5 \mathrm{~m} / \mathrm{s}$, the flame had shifted to the front of the porous matrix. As the equivalence ratio decreased, the flame propagation speed changed and the location of the flame began to retreat from the porous medium. The flame was easily blown out before stabilizing at a fixed location. However, when the inlet velocity was $0.6 \mathrm{~m} / \mathrm{s}$, the flame was contained in front of the porous matrix in the range of the equivalence ratio $0.85-1.0$. This was because of the relatively high flame propagation speed. Furthermore, the porous medium and the oxidation reaction on it helped stabilize the flame.

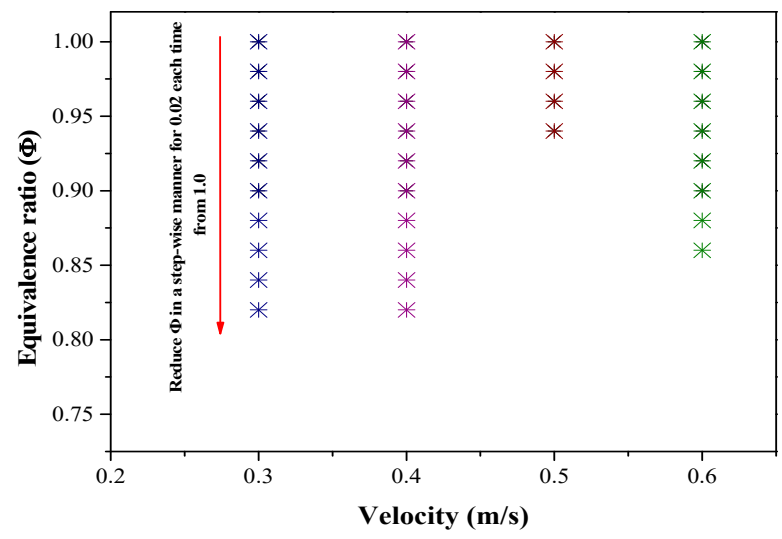

Figure 7. The flame extinction limit with different velocities.

From the above discussion, it seems that the range of stable combustion was wider for the smaller flow rate condition than for the higher flow rate condition. In other words, the addition of the porous matrix with catalysts could significantly extend the limits of stable combustion for lean mixtures.

The temperature variation with the equivalence ratio of the seven locations $\left(T_{1}-T_{7}\right)$ in the burner is presented in Figure 8. From the figure, it may be seen the temperature of all the points decreased slightly as the equivalence ratio decreased. This is mainly due to the fact that the heat produced by the methane combustion reaction was reduced. Besides, it was also found that the position of the flame that was near the highest temperature point almost did not change even though the equivalence ratio decreased from 1.0 to 0.84 . Obviously, the heterogeneous combustion on the catalyst surface played an important role. The heat released by methane oxidization helped to stabilize the flame. 


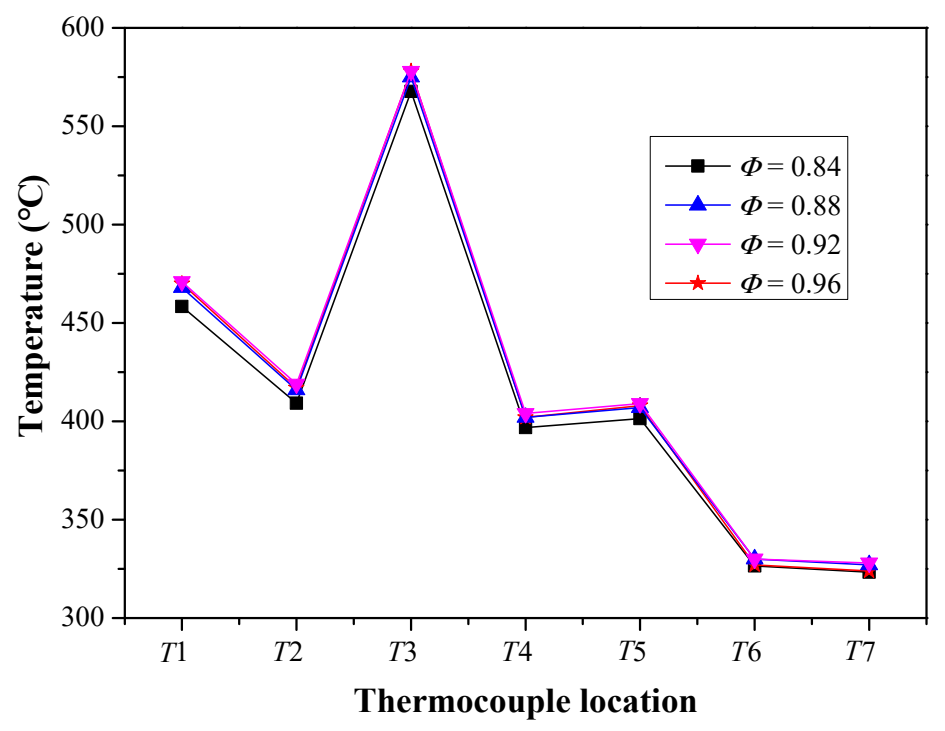

Figure 8. The temperature distribution of the combustor with different equivalence ratios, $v=0.4 \mathrm{~m} / \mathrm{s}$.

\subsection{Exhaust Gas Analysis}

Methane oxidation kinetics are very complicated because there are many possible elementary reactions. However, hydrocarbon combustion simplistically can be characterized as a two-step process. The first step involves the breakdown of the fuel to $\mathrm{CO}$, with the second step being the final oxidation of $\mathrm{CO}$ to $\mathrm{CO}_{2}$. Thus, $\mathrm{CO}$, an intermediate product in methane combustion, is extremely important to the oxidation of hydrocarbons [22]. In other words, maybe not all the $\mathrm{CO}$ would be oxidized to $\mathrm{CO}_{2}$ when the reactants went through the microcombustor, which meant that there were $\mathrm{CO}$ and $\mathrm{CO}_{2}$ in the products. Here, both methane conversion and $\mathrm{CO}_{2}$ and $\mathrm{CO}$ selectivity were investigated.

The fuel conversion $\left(\mathrm{X}_{\mathrm{CH} 4}\right)$ and $\mathrm{CO}_{2}$ and $\mathrm{CO}$ selectivity $\left(\mathrm{S}_{\mathrm{CO}_{2}}, \mathrm{~S}_{\mathrm{CO}}\right)$ were calculated using the following equations [24]:

$$
\begin{gathered}
X_{\mathrm{CH}_{4}}=\left(1-\frac{N_{\mathrm{CH}_{4}, \text { out }}}{N_{\mathrm{CH}_{4}, \text { out }}+N_{\mathrm{CO}_{2} \text { out }}+N_{\mathrm{CO}, \text { out }}}\right) \times 100 \% \\
\text { Selectivity of } k=\frac{N_{\text {out }, \mathrm{k}}}{N_{\text {out }}} \times 100 \%
\end{gathered}
$$

where $\mathrm{N}_{\mathrm{CH}_{4}, \text { out }}, \mathrm{N}_{\mathrm{CO}_{2}, \text { out }}$, and $\mathrm{N}_{\mathrm{CO}, \text { out }}$ represent the number of moles of unburnt $\mathrm{CH}_{4}, \mathrm{CO}_{2}$, and $\mathrm{CO}$ in the exhaust products, respectively. $N_{\text {out }}$ represents the total number of moles of $\mathrm{CO}$ and $\mathrm{CO}_{2}$ in the exhaust products. Subscript $k$ represents $\mathrm{CO}$ or $\mathrm{CO}_{2}$. From Equation (2), we can see that the conversion of methane included the partial oxidation of $\mathrm{CH}_{4}$ to $\mathrm{CO}$ and the complete oxidation of $\mathrm{CH}_{4}$ to $\mathrm{CO}_{2}$.

Figure 9 shows the conversion of methane on porous monolithic catalyst $\mathrm{Pd} / \mathrm{Al}_{2} \mathrm{O}_{3} / \mathrm{Fe}-\mathrm{Ni}$, with velocity and the equivalence ratio. It can be seen from the figure that although the conversion did change as the equivalence ratio varied, the methane conversion showed only the limited variation and was greater than $99.9 \%$. This of course proved the effectiveness of the catalysts on one hand, but on the other hand, it was also due to the fact that the conversion included both $\mathrm{CO}$ and $\mathrm{CO}_{2}$ (i.e., it included the incomplete oxidation of methane). Therefore, the equivalence ratio and inlet velocity had only very limited effects on the methane conversion. The reasons can be attributed to the following two aspects. The experiments conducted in this paper were all under oxygen-rich conditions $(\Phi \leq 1.0)$. Sufficient oxygen was supplied to react with methane. On the other hand, the Pd catalyst could greatly reduce the activation energy of the methane reaction and enhance the intensity of the combustion reaction. Moreover, a lot of active sites (Pds) were available for methane adsorption on the $\mathrm{Pd} / \mathrm{Al}_{2} \mathrm{O}_{3} / \mathrm{Fe}-\mathrm{Ni}$ catalyst surface, which made the combustion take place stably and fast at a relatively low temperature. When the flame was located near the entrance $(v=0.4 \mathrm{~m} / \mathrm{s}$, as seen from Figure $4 \mathrm{~b})$, the temperature 
$T_{3}$ on the catalyst surface was more than $550{ }^{\circ} \mathrm{C}$, which can be seen in Figure $5 \mathrm{a}$. According to our previous study [16], it was found that the $\mathrm{Pd} / \mathrm{Al}_{2} \mathrm{O}_{3} / \mathrm{Fe}-\mathrm{Ni}$ catalyst exhibited high catalytic activity for methane reaction and the conversion was more than $90 \%$ at a temperature of $500{ }^{\circ} \mathrm{C}$. For $v \geq 0.4 \mathrm{~m} / \mathrm{s}$, there was no doubt that the unburnt methane was almost oxidized by oxygen with the help of the activity of the catalyst when they flowed through the porous media. When the mixture entered into the combustor at $0.3 \mathrm{~m} / \mathrm{s}$ velocity, a homogenous combustion occurred at the entrance of inlet. Because of the complication of multistep chemical reactions, the mixture after combustion included unburnt methane and some unreacted hydrocarbons such as $\mathrm{CH}, \mathrm{CO}$, and $\mathrm{CO}_{2}$. Among these, it has been reported that $\mathrm{CO}$ is dominant. In fact, these gases would be oxidized with the activity of Pd when going through the porous matrix. The oxidation of methane must be performed at a high temperature. Nevertheless, the carbon monoxide could be converted to carbon dioxide at a much lower temperature. Therefore, the content of $\mathrm{CO}$ in exhaust gases would be higher at $0.3 \mathrm{~m} / \mathrm{s}$ than in other conditions.

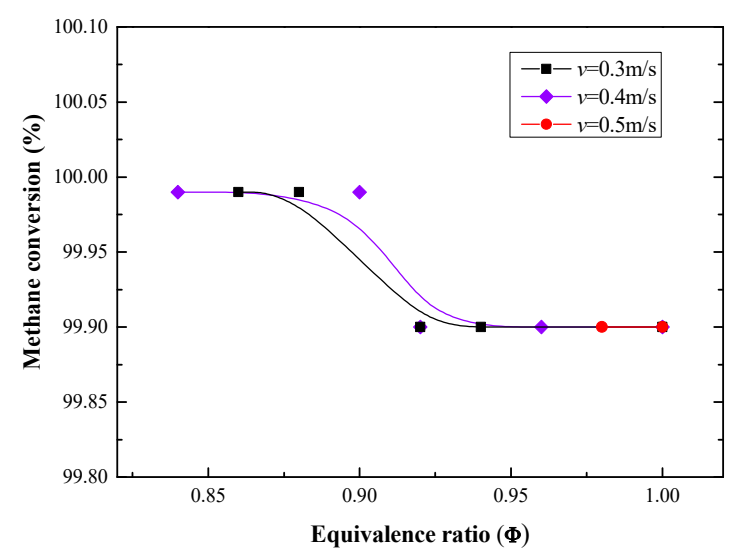

(a)

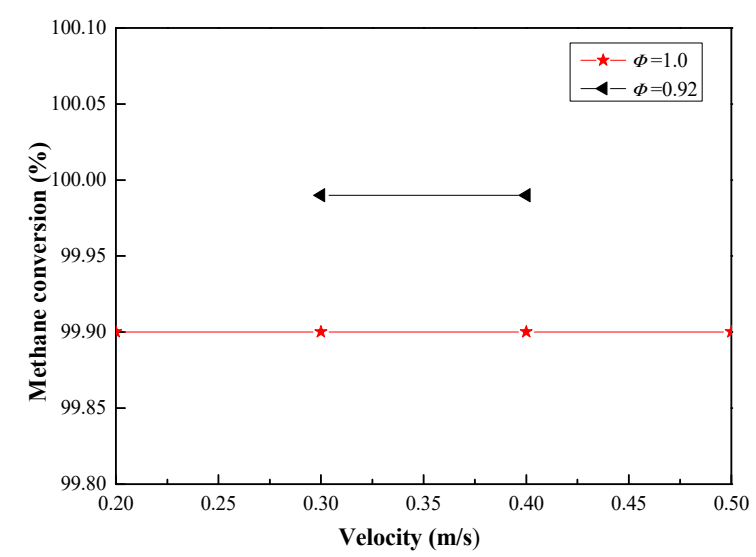

(b)

Figure 9. The conversion of methane catalytic combustion: (a) Different equivalence ratios; (b) different velocities.

The selectivity of $\mathrm{CO}_{2}$ and $\mathrm{CO}$ was given in Figure 10. It can be seen that the $\mathrm{CO}_{2}$ selectivity maintained a relatively high value of more than $91 \%$. Generally, it declined (Figure 10a) as the equivalence ratio increased. When $\Phi<0.90$, the $\mathrm{CO}_{2}$ selectivity was greater than $99.5 \%$ and the selectivity value of $\mathrm{CO}_{2}$ achieved the minimum at $\Phi=1.00$. On the contrary, the $\mathrm{CO}$ selectivity presented an exactly different trend. As expected, more oxygen was available to help the methane or carbon monoxide be oxidized into $\mathrm{CO}_{2}$ as the equivalence ratio decreased. The chances of the collision of $\mathrm{O}_{2}$ molecules with $\mathrm{CH}_{4}$ and $\mathrm{CO}$ molecules were increased in oxygen-rich conditions, which would improve the combustion reaction to some extent. This explains why the $\mathrm{CO}$ selectivity increased and the $\mathrm{CO}_{2}$ selectivity decreased with the equivalence ratio.

In addition, the mixture flow rate had a limited influence on the selectivity of $\mathrm{CO}_{2}$ and $\mathrm{CO}$. As the inlet velocity decreased from 0.4 to 0.3 , the selectivity of $\mathrm{CO}_{2}$ went down only a little. That is, the unreacted $\mathrm{CO}$ in the combustion at $0.3 \mathrm{~m} / \mathrm{s}$ was more than that at $0.4 \mathrm{~m} / \mathrm{s}$, which can be seen in Figure 10b. At $0.5 \mathrm{~m} / \mathrm{s}$, the selectivity curves were located between the two lines of $v=0.3 \mathrm{~m} / \mathrm{s}$ and $v=0.4 \mathrm{~m} / \mathrm{s}$. The reason was not very clear. It was probably due to the relatively short residence time for reactants inside the burner. Actually, the flame at $0.5 \mathrm{~m} / \mathrm{s}$ had shifted downstream from the entrance to the front of the porous matrix. 


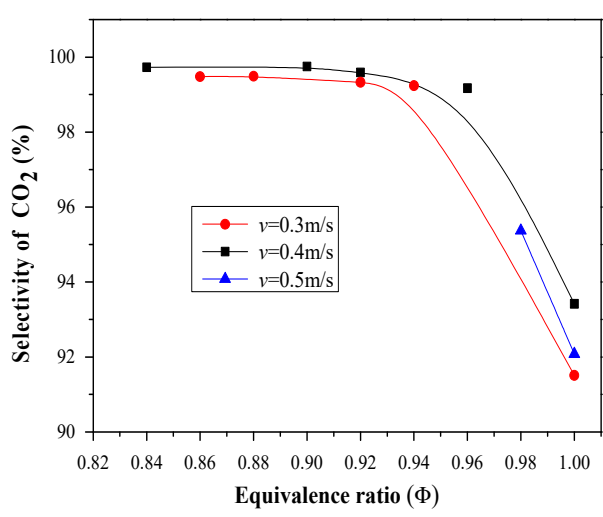

(a) $\mathrm{CO}_{2}$

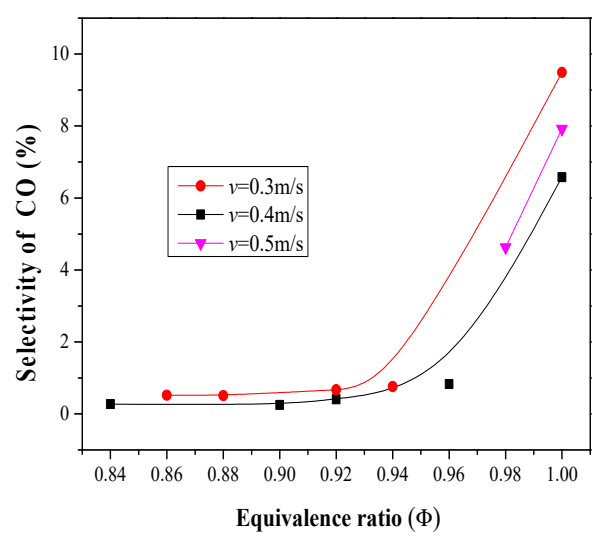

(b) $\mathrm{CO}$

Figure 10. Product selectivity of $\mathrm{CO}_{2}$ and $\mathrm{CO}$ : (a) $\mathrm{CO}_{2} ;$ (b) $\mathrm{CO}$.

Additionally, $\mathrm{H}_{2}$ was detected in the exhaust gases. It was reported that the $\mathrm{Pd}$ catalyst had exhibited a very high activity for the reaction of $\mathrm{CO}$ and vapor under an oxygen-deficient environment even at low temperature [25]. $\mathrm{H}_{2}$ was produced in this reaction with the activity of the catalyst, according to Equation (4) [26]:

$$
\mathrm{H}_{2} \mathrm{O}+\mathrm{CO} \rightarrow \mathrm{H}_{2}+\mathrm{CO}_{2}
$$

The $\mathrm{H}_{2}$ yield was calculated using the following equations [27]:

$$
\begin{gathered}
Y_{\mathrm{H}_{2}}=X_{\mathrm{CH}_{4}} S_{\mathrm{H}_{2}}, \\
S_{\mathrm{H}_{2}}=\frac{N_{\mathrm{H}_{2} \text { out }}}{N_{\mathrm{H}_{2}, \text { out }}+N_{\mathrm{H}_{2} \mathrm{O}, \text { out }}},
\end{gathered}
$$

where $Y_{\mathrm{H} 2}$ presents the yield of $\mathrm{H}_{2}, S_{\mathrm{H} 2}$ presents the selectivity of $\mathrm{H}_{2}$ that was calculated by Equation (6), and $\mathrm{N}_{\mathrm{H}_{2}, \text { out }}$ and $\mathrm{N}_{\mathrm{H}_{2} \mathrm{O} \text {,out }}$ respectively represent the number of moles of $\mathrm{H}_{2}$ and gas-phase $\mathrm{H}_{2} \mathrm{O}$ in the exhaust products. $\mathrm{X}_{\mathrm{CH} 4}$ is the corresponding fuel conversion calculated by Equation (2). Figure 11 shows the product yield of $\mathrm{H}_{2}$ at different equivalence ratios. As can be seen from this figure, the product yield of $\mathrm{H}_{2}$ was maintained at zero if the equivalence ratio was smaller than 0.94 . Once the equivalence ratio was larger than 0.94 , a certain amount of hydrogen was detected from the exhaust gases. When the equivalence ratio approached $1.0(\Phi=0.98, \Phi=1.0)$, the lean oxygen condition resulted in the $\mathrm{H}_{2} \mathrm{O}-\mathrm{CO}$ reaction and more $\mathrm{H}_{2}$ was produced than in the low equivalence ratio condition. However, it could not occur at $\Phi<0.94$ because of the oxygen-rich environment.

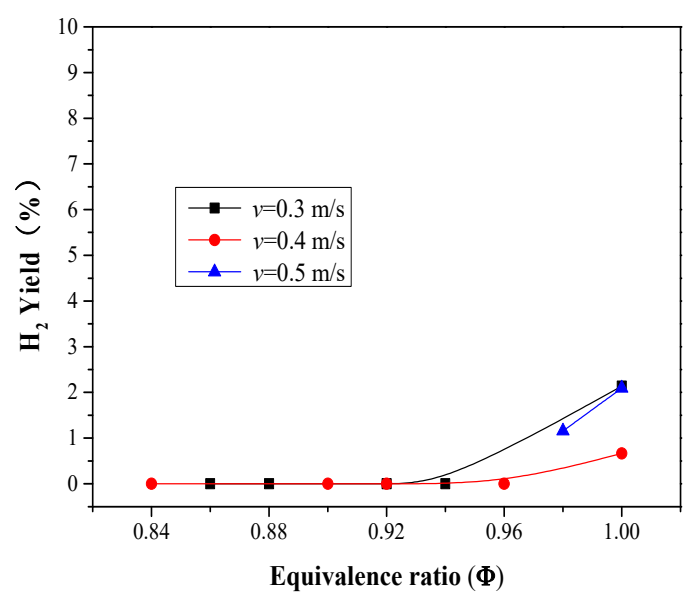

Figure 11. Product yield of $\mathrm{H}_{2}$. 


\section{Experiment Design}

\subsection{Experiment Facility and Combustor}

The schematic diagram of the experiment setup is shown in Figure 12. The methane and air were supplied by a methane tank (99.99\% purity) and a synthetic air tank $\left(21 \% \mathrm{O}_{2}+79 \% \mathrm{~N}_{2}\right)$, respectively. Two mass flow controllers were used to control the flow rates of methane and air in the combustor. Thus, different $\mathrm{CH}_{4}$ /air equivalence ratios and mixture flow rates were available. The mass flow controllers (Seven Star ${ }^{\circledR}$ Mass Flow Controller, Model CS200-A, Beijing, China), with an accuracy of $\pm 1 \%$, have a full-scale range of $0-400 \mathrm{~mL} / \mathrm{min}$ and $0-3 \mathrm{~L} / \mathrm{min}$ for the methane and air flow meters, respectively. The fuel and air were mixed sufficiently in the mixer, which was comprised of 21 pieces of stainless steel mesh. In order to prevent backfire, the mixed gases had to go through the flame arrester before flowing into the combustor.

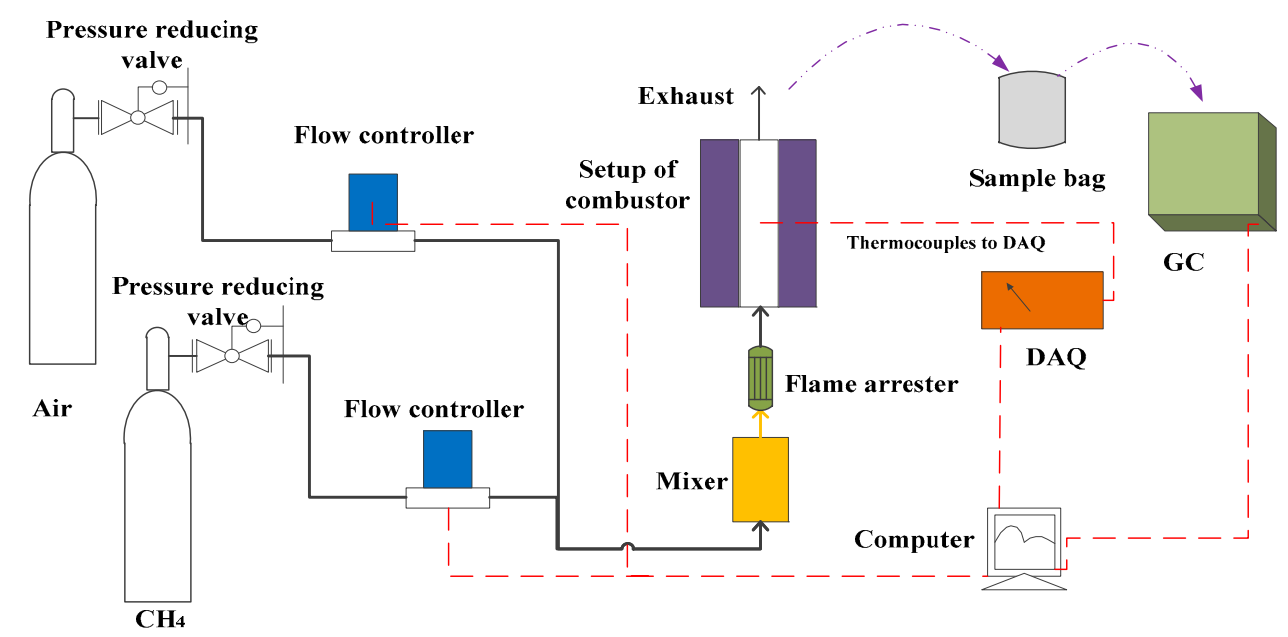

Figure 12. The schematic diagram of the experiment setup.

Figure 13 shows the basic structure of the combustor. A single tube combustor was used, which was fabricated from quartz glass. The tube had an inner diameter of $5 \mathrm{~mm}$, an outer diameter of $9 \mathrm{~mm}$, and a length of $90 \mathrm{~mm}$. A catalyst $\left(\mathrm{Pd} / \mathrm{Al}_{2} \mathrm{O}_{3} / \mathrm{Ni}-\mathrm{Fe}\right)$ was filled in the middle of the tube. Seven K-type thermocouples were placed equidistantly $(6 \mathrm{~mm}$ each) in the combustor to measure the temperature distribution of the combustion chamber, as shown in Figure 13a. Thermocouples of $T_{3}$ and $T_{5}$ were located along the axis of the tube. Others were located along the inner wall of the tube. A high-voltage $(6 \mathrm{kV})$ spark generator was used to ignite the fuel-air mixture with ignition electrodes located in the combustion chamber. The combustor setup was composed of a stainless steel tube $(29 \mathrm{~mm}$ in inner diameter, $1 \mathrm{~mm}$ in thickness), which was used to reduce heat loss. In addition, the steel tube featured a quartz transparent window that allowed observation of the flame, as shown in Figure 13b. The outer wall of the stainless steel casing was insulated with ceramic fiber board insulation to reduce heat loss from the burner and to increase the repeatability of the experiments.

The exhaust gases were collected using aluminum foil sample bags, and were then tested using gas chromatography (GC, Agilent ${ }^{\circledR}$, Model 7890A, Palo Alto, CA, USA) equipped with a thermal conductivity detector (TCD) and a flame ionization detector (FID). Two primary parameters, methane conversion and $\mathrm{CO}_{2}$ and $\mathrm{CO}$ selectivity, were investigated to determine the effectiveness of the catalyst and the completeness of combustion. 


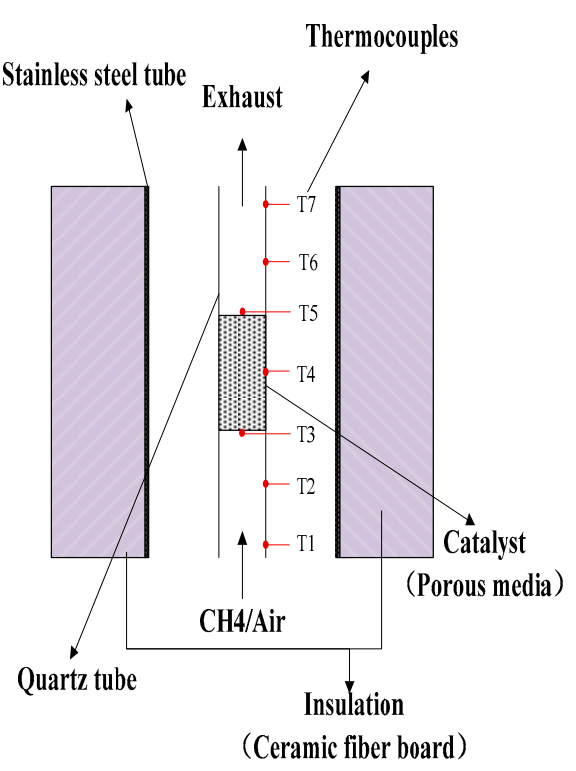

(a)

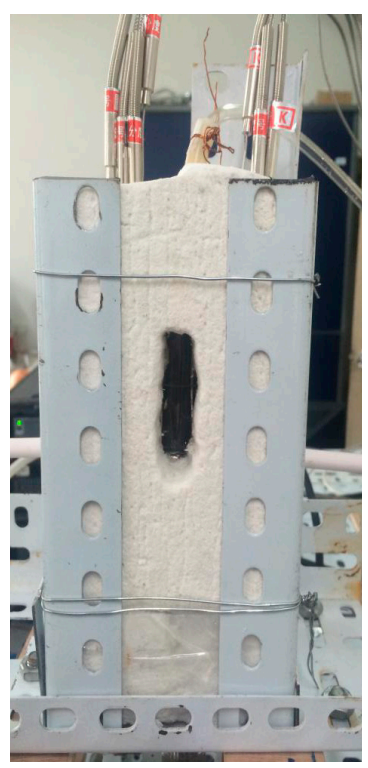

(b)

Figure 13. The combustor: (a) The schematic diagram of the catalytic combustor; (b) photograph of the combustor in setup.

\subsection{Experiment Procedure}

The fuel-air mixture was allowed to enter the combustor from the bottom of the combustion chamber, as seen in Figure 13a. Then the mixed gases with a stoichiometric ratio of $\Phi=1.0$ was ignited by the spark generator at a required velocity.

First, a stable combustion flame was available, and sometimes it may take a long time. In other words, the temperature changed less than $3{ }^{\circ} \mathrm{C}$ and the flame remained at a steady position for more than $5 \mathrm{~min}$. The position and state of the flame could be observed through the quartz window.

Second, the exhaust gases were collected by aluminum foil sample bags and were injected into the GC to detect the composition and content using a syringe.

Finally, the experiment conditions were changed. For example, the equivalent ratio $\Phi$ was regulated in a step-wise manner of 0.02 each time by increasing the air flow and decreasing the fuel flow, keeping the mixture flow constant simultaneously. When the flame went out, the corresponding equivalence ratio $\Phi$ was defined as the extinction limit (at lean condition) at which the combustion was no longer sustainable. During the combustion process, the temperatures measured by thermocouples were automatically collected every $10 \mathrm{~s}$ using a data acquisition instrument (DAQ, Agilent ${ }^{\circledR}$, Model 34972A, Palo Alto, CA, USA). As the catalyst was filled in the middle of the tube, the velocity at the entrance was different from the velocity inside the catalyst. In this paper, the velocity referred to the inlet velocity.

\section{Conclusions}

In the present work, the methane catalytic combustion in a $5 \mathrm{~mm}$ in diameter microcombustor embedded with a $\mathrm{Pd} / \mathrm{A}_{2} \mathrm{O}_{3} / \mathrm{Fe}-\mathrm{Ni}$ catalyst prepared by impregnation was experimentally investigated. From the experiment results and the phenomena observed, the following conclusions could be drawn.

(a) The stoichiometric ratio $(\Phi=1.0)$ of the methane and air mixture could be ignited at $v=0.2-0.6 \mathrm{~m} / \mathrm{s}$, and the ignition startup procedure could be divided into three stages: (1) The internal temperature inside the burner rose sharply, (2) the internal temperature inside the burner dropped slowly, and (3) the burner reached a steady state and the temperature showed an unchanging trend. 
(b) The results showed that the velocity of premixed gases had a great influence on the catalytic combustion of methane. The larger the velocities, the higher the temperature was and the brighter the flame was, and the flame location shifted from downstream of the entrance to the front of the porous monolithic catalyst with the increase of the mixture flow rate. The catalytic combustion and the porous medium contributed a lot to stabilize the flame in the fixed location and extend the low limits of stable combustion for lean mixtures.

(c) The equivalence ratio also had a large essential impact on the combustion, especially for the lean mixture of methane and air. It seemed the addition of the porous matrix with catalysts could significantly extend the limits of stable combustion, and it worked better with the smaller flow rate than with the higher flow rate condition.

(d) The conversion of methane to $\mathrm{CO}$ and $\mathrm{CO}_{2}$ was greater than $99 \%$ under the conditions of our research. However, the $\mathrm{CO}_{2}$ selectivity decreased and the $\mathrm{CO}$ selectivity increased as the equivalence ratio increased. When the equivalence ration $\Phi$ was between 0.94 and 1.0, a little amount of hydrogen was produced by the $\mathrm{H}_{2} \mathrm{O}-\mathrm{CO}$ reaction due to the lack of oxygen.

Theoretical analysis on the effects of a porous medium with catalysts on combustion is in progress in order to understand the catalytic combustion mechanism and describe the chain reaction. In addition, a more detailed investigation into the influences of impurities on catalyst deactivation will be conducted to evaluate the stability and lifetime of monolithic catalysts.

Author Contributions: Z.L. and Y.L. conceived and designed the experiments; C.L. performed the experiments; C.L. and Y.L. analyzed the data; C.L. prepared the manuscript and Y.L., Z.L. and F.L. revised and corrected the manuscript.

Acknowledgments: This work was supported by the National Natural Science Foundation of China (NO. 51306005) and the Beijing Natural Science Foundation of China (NO: 3132011).

Conflicts of Interest: The authors declare no conflict of interest.

\section{References}

1. Yadav, S.; Yamasani, P.; Kumar, S. Experimental studies on a micro power generator using thermo-electric modules mounted on a micro-combustor. Energy Convers. Manag. 2015, 99, 1-7. [CrossRef]

2. Fernandez-Pello, A.C. Micro-power generation using combustion: Issues and approaches. Proc. Combust. Inst. 2002, 29, 883-898. [CrossRef]

3. Stelzner, B.; Keramiotis, C.; Voss, S.; Founti, M.A.; Trimis, D. Analysis of the flame structure for lean methane-air combustion in porous inert media by resolving the hydroxyl radical. Proc. Combust. Inst. 2015, 35, 3381-3388. [CrossRef]

4. Mueller, K.T.; Waters, O.; Bubnovich, V.; Orlovskaya, N.; Chen, R.H. Super-adiabatic combustion in $\mathrm{Al}_{2} \mathrm{O}_{3}$ and $\mathrm{SiC}$ coated porous media for thermoelectric power conversion. Energy 2013, 56, 108-116. [CrossRef]

5. Ismail, A.K.; Abdullah, M.Z.; Zubair, M.; Jamaludin, A.R.; Ahmad, Z.A. Effect of ceramic coating in combustion and cogeneration performance of $\mathrm{Al}_{2} \mathrm{O}_{3}$ porous medium. J. Energy Inst. 2016, 89, 81-93. [CrossRef]

6. Li, J.W.; Huang, J.H.; Yan, M.; Zhao, D.; Zhao, J.Y.; Wei, Z.J.; Wang, N.F. Experimental study of n-heptane/air combustion in meso-scale burners with porous media. Exp. Therm. Fluid Sci. 2014, 52, 47-58. [CrossRef]

7. Kaisare, N.S.; Deshmukh, S.R.; Vlachos, D.G. Stability and performance of catalytic microreactors: Simulations of propane catalytic combustion on Pt. Chem. Eng. Sci. 2008, 63, 1098-1116. [CrossRef]

8. Maruta, K.; Takeda, K.; Ahn, J.; Borer, K.; Sitzki, L.; Ronney, P.D.; Deutschmann, O. Extinction limits of catalytic combustion in microchannels. Proc. Combust. Inst. 2002, 29, 957-963. [CrossRef]

9. Kaisare, N.S.; Vlachos, D.G. A review on microcombustion: Fundamentals, devices and applications. Prog. Energy Combust. Sci. 2012, 38, 321-359. [CrossRef]

10. Wang, Y.; Zhou, Z.J.; Yang, W.J.; Zhou, J.H.; Liu, J.Z.; Wang, Z.H.; Cen, K.F. Combustion of hydrogen-air in micro combustors with catalytic Pt layer. Energy Convers. Manag. 2010, 51, 1127-1133. [CrossRef]

11. Sang, L.X.; Sun, B.; Tan, H.Y.; Du, C.X.; Wu, Y.T.; Ma, C.F. Catalytic reforming of methane with $\mathrm{CO}_{2}$ over metal foam based monolithic catalysts. Int. J. Hydrogen Energy 2012, 37, 13037-13043. [CrossRef] 
12. Bortolozzi, J.P.; Gutierrez, L.B.; Ulla, M.A. Synthesis of $\mathrm{Ni} / \mathrm{Al}_{2} \mathrm{O}_{3}$ and $\mathrm{Ni}-\mathrm{Co} / \mathrm{Al}_{2} \mathrm{O}_{3}$ coatings onto AISI 314 foams and their catalytic application for the oxidative dehydrogenation of ethane. Appl. Catal. A 2013, 452, 179-188. [CrossRef]

13. Cimino, S.; Gerbasi, R.; Lisi, L.; Mancino, G.; Musiani, M.; Vázquez-Gómez, L.; Verlato, E. Oxidation of $\mathrm{CO}$ and $\mathrm{CH}_{4}$ on Pd-Fecralloy foam catalysts prepared by spontaneous deposition. Chem. Eng. J. 2013, 230, 422-431. [CrossRef]

14. Liu, Y.; Edouard, D.; Nguyen, L.D.; Begin, D.; Nguyen, P.; Pham, C.; Pham-Huu, C. High performance structured platelet milli-reactor filled with supported cobalt open cell $\mathrm{SiC}$ foam catalyst for the Fischer-Tropsch synthesis. Chem. Eng. J. 2013, 222, 265-273. [CrossRef]

15. Spadaccini, C.M.; Peck, J.; Waitz, I.A. Catalytic combustion systems for microscale gas turbine engines. J. Eng. Gas Turbines Power 2007, 129, 49-60. [CrossRef]

16. Li, Y.X.; Luo, C.M.; Liu, Z.L.; Sang, L.X. Catalytic oxidation characteristics of $\mathrm{CH}_{4}$-air mixtures over metal foam monoliths. Appl. Energy 2015, 156, 756-761. [CrossRef]

17. Robayo, M.D.; Beaman, B.; Hughes, B.; Delose, B.; Orlovskaya, N.; Chen, R.H. Perovskite catalysts enhanced combustion on porous media. Energy 2014, 76, 477-486. [CrossRef]

18. Landi, G.; Benedetto, A.D.; Barbato, P.S.; Russo, G.; Srli, V.D. Transient behavior of structured $\mathrm{LaMnO}_{3}$ catalyst during methane combustion at high pressure. Chem. Eng. Sci. 2014, 116, 350-358. [CrossRef]

19. Srli, V.D.; Barbato, P.S.; Benedetto, A.D.; Landi, G. Start-up behavior of a $\mathrm{LaMnO}_{3}$ partially coated monolithic combustor at high pressure. Catal. Today 2015, 242, 200-210. [CrossRef]

20. Benedetto, A.D.; Landi, G.; Sarli, V.D.; Barbato, P.S.; Pirone, R.; Russo, G. Methane catalytic combustion under pressure. Catal. Today 2012, 197, 206-213. [CrossRef]

21. Li, Y.X.; Wu, T.; Luo, C.M.; Liu, Z.L. Hydrogen-assisted catalytic oxidation characteristics of $\mathrm{CH}_{4} / \mathrm{Air}$ mixtures over metal foam based monolithic catalyst. Int. J. Energy A Clean Environ. 2016, 16, 81-89. [CrossRef]

22. Turns, S.R. An Introduction to Combustion, 2nd ed.; McGraw-Hill Book Co.: New York, NY USA, 2000; p. 19.

23. Zhang, Y.S.; Zhou, J.H.; Yang, W.J.; Liu, M.S.; Cen, K.F. The experimental study of hydrogen and air premixed combustion in microscale T. style tube. Proc. CSEE 2005, 25, 128-131.

24. Wierzbicki, T.A.; Lee, I.C.; Gupta, A.K. Rh assisted catalytic oxidation of jet fuel surrogates in a meso-scale combustor. Appl. Energy 2015, 145, 1-7. [CrossRef]

25. Sun, X.; Lin, J.; Zhou, Y.; Sun, X.; Li, L.; Su, Y.; Wang, X.; Zhang, T. FeO supported single-atom Pd bifunctional catalyst for water gas shift reaction. AIChE J. 2017, 63, 4022-4031. [CrossRef]

26. Wierzbicki, T.A.; Lee, I.C.; Gupta, A.K. Combustion of propane with Pt and Rh catalysts in a meso-scale heat recirculating combustor. Appl. Energy 2014, 130, 350-356. [CrossRef]

27. Nogare, D.D.; Degenstein, N.J.; Horn, R.; Canu, P.; Schmidt, L.D. Modeling spatially resolved data of methane catalytic partial oxidation on Rh foam catalyst at different inlet compositions and flowrates. J. Catal. 2011, 277, 134-148. [CrossRef]

(C) 2018 by the authors. Licensee MDPI, Basel, Switzerland. This article is an open access article distributed under the terms and conditions of the Creative Commons Attribution (CC BY) license (http:/ / creativecommons.org/licenses/by/4.0/). 